\title{
Life-Threatening Necrotizing Fasciitis of the Neck: A Case Report
}

\author{
Ismail Iynen $^{\mathrm{a}, \mathrm{b}}$, Imran San ${ }^{\mathrm{a}}$, Ferhat Bozkus ${ }^{\mathrm{a}}$, Halil Beklen ${ }^{\mathrm{a}}$
}

\begin{abstract}
Necrotizing fasciitis is a rare, progressive and life-threatening bacterial infection which spreads with frightening speed along the fascial planes and subcutaneous tissue resulting in extensive tissue necrosis and often death. Rapidly spreading necrosis often causes systemic sepsis, toxic shock syndrome and multiorgan failure. Necrotizing fasciitis of the neck is rare and commonly has a dental or pharyngeal origin. Factors affecting the success of the treatment of necrotizing fasciitis are early diagnosis, appropriate antibiotics and surgical debridement. This article is presented in a patient with necrotizing fasciitis of the neck originated from odontogenic infection. Clinical features, pathogenesis and treatment of the case are discussed with the literature.
\end{abstract}

Keywords: Neck; Necrotizing fasciitis; Soft tissue infection; Debridement

\section{Introduction}

Cervical necrotizing fasciitis is a fulminant infection that spreads with high mortality, and the necrosis of connective tissue that spreads along the facial plane. It was first clinically defined by Joseph Jones in 1871, during the U. S. Civil

Manuscript accepted for publication August 23, 2011

${ }^{a}$ Department of Otolaryngology-Head and Neck Surgery, Harran University, Sanliurfa, Turkey

${ }^{\mathrm{b}}$ Correspondence author: Ismail Iynen, Department of Otolaryngology-Head and Neck Surgery, Harran University Hospital, 63300 Sanliurfa, Turkey. Email: iiynen@hotmail.com
War. In 1918, Pfanner diagnosed a patient with a beta- hemalotic streptococcal infection and designated it "necrotizing erysipelas". Wilson was the first person to use the term necrotizing fasciitis (NF) in 1952 [1].

In general, the disease is limited only with the subcutaneous tissue and muscle involvement is rare. The fact that necrotizing fasciitis causes tissue necrosis and spreads rapidly along the facial plane is due to its being polybacterial and the synergistic effect of enzymes formed by the bacteria. The most common factor is pathogen streptococcal. While involvement in the head and neck area is rare, it is more common in extremities, the genital region, and the abdomen [2].

The main reasons for the disease are odontogenic infections and trauma. The disease frequently develops in individuals that have an insufficient and low immune system. It is commonly seen in middle aged individuals. The early stage of the disease looks like abscess and cellulite. The covering skin is usually red and taut. Hyperesthesia or anaesthesia can be identified by touch. This benign image is the most important reason behind late diagnosis. The diagnosis can be made using a computerised tomography (CT) and subcutaneous gas formation. Treatment of the disease is early diagnosis, a careful aggressive debridement, parenteral antibiotic treatment, and supporting treatment controlling an underlying preparative, and aggravating factors $[1,3]$.

This article presents a case of NF that develops in the neck after a dental infection; the clinical properties, pathogenesis, and treatment of the disease were discussed together with the relevant literature.

\section{Case Report}

Male patient, aged 48, registered with our polyclinic complaining of neck pains and swellings, and difficulty opening their mouths. In their histories, patients stated that they registered with our clinic due to increasing complaints regardless of the oral antibiotherapy they had received approximately a week ago for their tooth infection. According to their physical examinations, there was oedema and hyperaemia covering an area incorporating both submandibular regions and the left sublingual region. Patients experienced neck pains,

doi:10.4021/jcs103e 


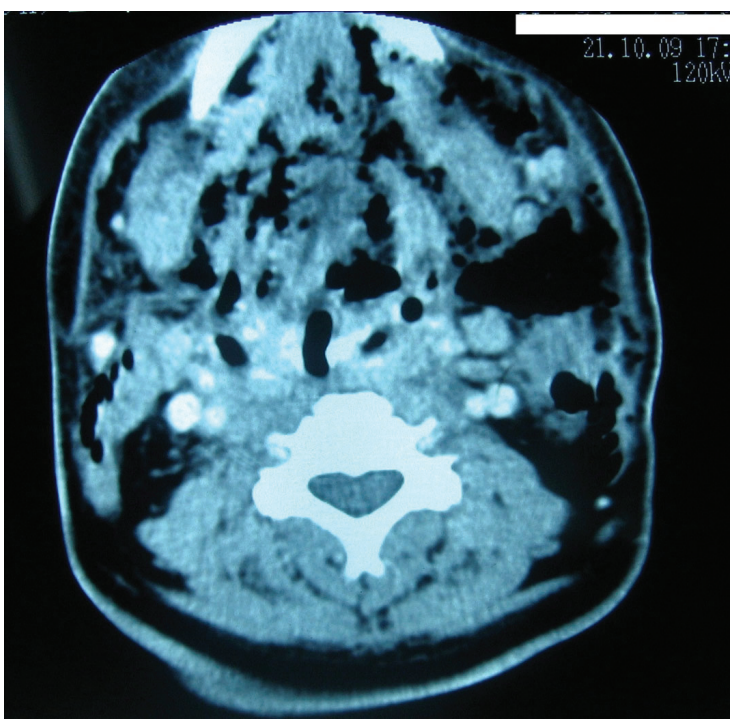

Figure 1. CT scan of head and neck showing air collections in bilateral submandibular, submental and cervical region.

limitations of neck movements, and had difficulty opening their mouths. According to the oral examination, there was oedema in the floor of mouth, the second lower left molar tooth was infected, and the state of general oral hygiene was bad. The patient had no significant breathing difficulties. Examining the patient's background proved that they had received treatment for cardiac complaints and had an angiography five years ago. Their arterial blood pressure was $130 / 80 \mathrm{~mm} \mathrm{Hg}$, their pulse was 92 beat/minute, their breath/ minute was 16 , their body temperature was $36.8^{\circ} \mathrm{C}$ using axial measurement, their white blood cells count was 21000 , their haemoglobin level was $10.52 \mathrm{gr} / \mathrm{dL}$, their hematocrit level was 29.86, their CRP was $56 \mathrm{mg} / \mathrm{dL}$, their glucose was $117 \mathrm{mg} / \mathrm{dL}$, and their Ca was $10.2 \mathrm{mg} / \mathrm{dL}$. Neck CT showed widespread subcutaneous air, oedema in tissues, micro abscess focuses that hold together deep tissues (Fig. 1). As a result patients were pre-diagnosed with necrotizing fasciitis, and referred to the intensive care unit as inpatients. In line with recommendations from the infectious diseases department they were started on a course of $3 \times 4.5$ gr tazocin intravenously. In the event that patients did not respond to antibiotherapy within 24 hours, and suffered from cardiac and respiratory problems, an emergency tracheotomy was performed; an incision was made in the left submandibular region of the neck. Necrosis was seen in the facial and subcutaneous tissues, as well as plenty of purulent material in the incision region. Necrosis tissues and purulent materials were debride, and the wound was left open. The wound was dressed and debrided daily, and closed with antibiotic gas. The wound was monitored (multidisciplinary) for approximately a month, and was closed in the event that the wound area epithelised (Fig. 2). Patients whose general state improved, and who were planned to be monitored by the otolar-

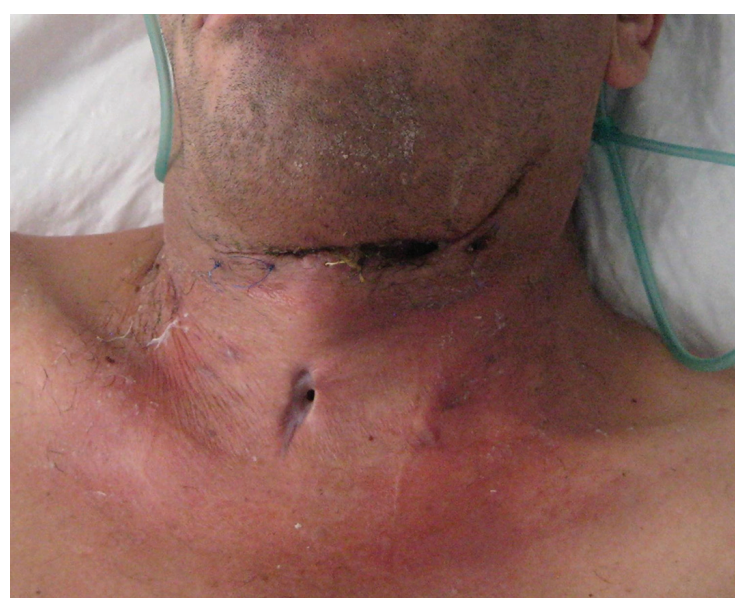

Figure 2. A month after the appearance of the patient.

yngology died in conclusion of their myocardial infarction.

\section{Discussion}

Cervical necrotizing fasciitis is an infection that rapidly progresses on the facial plane, even if cases are rare. It comprises $2.6 \%$ of all head and neck infections. It is more common in males. According to literature, its mortality rate changes between $19 \%$ and $40 \%$ [2]. The place it is the most frequently seen is dental pathology, closely followed by parapharyngeal and peritonsillar infections. The mandibular second and third molar teeth are the common reason behind odontogene-based infections. The fact that these teeth reach beneath the region where the mylohyoid muscle sticks to the mandibula enables infections caused by these teeth to reach the submandibular region. The infection may progress to the skull base in the upper region, and the thorax and the mediastinum in the lower region [3-5]. Our patient suffered from necrotizing fasciitis caused a necrosis, which spread to the submandibular region after an infected second lower molar tooth and finally progressed over a broad region of the neck.

The disease starts suddenly and violently with a high temperature. The infection causes necrosis in subcutaneous tissue as a result of intense lymphocytic infiltration, vascular thrombosis, and oedema as it spreads among muscle layers. The layer covering the skin is sensitive, red and has an oedema. As necrosis advances the skin becomes dull and numb; after which it becomes dusky. Subcutaneous tissue is dull and suffers from oedema; there is flix similar to melted butter and dishwater. In general, the infection in necrotizing fasciitis is poly-microbial. Its most common factor is Streptococcals. Anaerobic pathogens were identified in $30 \%$ of patients $[6,7]$. Streptococcal spp formed in the culture of our case.

The disease progresses more rapidly in patients that are diabetes, have chronic kidney failure, have insufficient immune systems, and have undergone surgery, trauma, and 
radiotherapy previously $[5,8]$. Our patient has no chronic illnesses; however, they did suffer from dehydration and malnutrition during their illnesses because of their oral intake disorder.

Suitable radiological examinations should be requested as soon as possible in order to determine the extent of the disease, and to correctly evaluate the airway of the patient. Standard radiographic assessments and CT examinations fall among these examinations. The $\mathrm{CT}$ enables us to see the formation of subcutaneous gas and abscess. The CT of our case helps us identify subcutaneous gas and micro-abscesses. Even though the CT image does not illustrate significant pathology, it helps guide surgical intervention $[6,9]$.

The first step of treatment is checking the airway. Medical treatment requires a broad range of antibiotics together with fluid and electrolyte replacements. Surgical treatment requires a wide faciotomy incision, exploring facial planes together with drainage and excision of all necrosis tissues. Wound care should be carried out using local antibiotic pomades. Once culture results are obtained, antibiotic treatment should be modified to be effective on the effective organisms. In general, hypocalcemia is seen in patients during the disease, as fatty acids, formed during subcutaneous fat necrosis, combine with calcium to form soap. Hyperbaric oxygen and intravenous immune globulin treatment decreases the mortality rate $[6,7,10]$.

\section{Conclusion}

Even though necrotizing fasciitis is rarely seen in the head and neck region, a clinician must be aware that the illness may occur and be sharp in diagnosing the disease. Rapid and suitable medical and surgical treatment, applied before the disease spreads, and before mortality-increasing complications arise, increases the rate of success.

\section{References}

1. Lorenzini G, Picciotti M, Di Vece L, Pepponi E, Brindisi
L, Vessio V, Maffei M, et al. Cervical necrotizing fasciitis of odontogenic origin involving the temporal region-a case report. J Craniomaxillofac Surg. 2011;39(8):570573.

2. Zhang WJ, Cai XY, Yang C, Zhou LN, Cai M, Lu XF, Zheng LY, et al. Cervical necrotizing fasciitis due to methicillin-resistant Staphylococcus aureus: a case report. Int J Oral Maxillofac Surg. 2010;39(8):830834.

3. Bono G, Argo A, Zerbo S, Triolo V, Procaccianti P. Cervical necrotizing fasciitis and descending necrotizing mediastinitis in a patient affected by neglected peritonsillar abscess: a case of medical negligence. J Forensic Leg Med. 2008;15(6):391-394.

4. Feinerman IL, Tan HK, Roberson DW, Malley R, Kenna MA. Necrotizing fasciitis of the pharynx following adenotonsillectomy. Int $\mathrm{J}$ Pediatr Otorhinolaryngol. 1999;48(1):1-7.

5. Hohlweg-Majert B, Weyer N, Metzger MC, Schon R. Cervicofacial necrotizing fasciitis. Diabetes Res Clin Pract. 2006;72(2):206-208.

6. Bilbault P, Castelain V, Schenck-Dhif M, Schneider F, Charpiot A. Life-threatening cervical necrotizing fasciitis after a common dental extraction. Am J Emerg Med. 2008;26(8):971 e975-977.

7. Mao JC, Carron MA, Fountain KR, Stachler RJ, Yoo GH, Mathog RH, Coticchia JM. Craniocervical necrotizing fasciitis with and without thoracic extension: management strategies and outcome. Am J Otolaryngol. 2009;30(1):17-23.

8. Delaney P, Rafiq R, Dodd M. Craniocervical necrotising fasciitis--an interesting case with review of the literature. Br J Oral Maxillofac Surg. 2010;48(4):e1-4.

9. Obiechina AE, Arotiba JT, Fasola AO. Necrotizing fasciitis of odontogenic origin in Ibadan, Nigeria. Br J Oral Maxillofac Surg. 2001;39(2):122-126.

10. Flanagan CE, Daramola OO, Maisel RH, Adkinson C, Odland RM. Surgical debridement and adjunctive hyperbaric oxygen in cervical necrotizing fasciitis. Otolaryngol Head Neck Surg. 2009;140(5):730-734. 